Cadernos do IL e Cadernos do IL e Cadernos do IL e Cadernos do IL e Cadernos do IL e Cadernos do IL

\title{
ANÁLISE DE UMA RESENHA MIDIÁTICA SOB O PONTO DE VISTA DA ESQUEMATIZAÇÃO
}

\author{
Silvana Kissmann*
}

RESUMO: Tomando por base o modelo de comunicação de Grize (1990) e o conceito de esquematização propostos a partir da lógica natural; apresenta-se a análise de uma resenha midiática para investigar os processos de construção e de coconstrução de objetos de discurso. Realiza-se a análise em duas etapas; na primeira, descreve-se a situação de comunicação com base nas categorias de Charaudeau (2006, 2009); na segunda, identifica-se o processo de construção de objetos de discurso através do exame de formas linguísticas que revelam quais pré-construídos culturais e representações são mobilizados para construir o ponto de vista da autora sobre a obra examinada - ou seja, a esquematização proposta. Os resultados mostram a produtividade que o modelo de comunicação de Grize pode conferir à análise.

PALAVRAS-CHAVE: análise de resenha midiática - esquematização - objetos de discurso

RESUME: S'appuyant sur le modèle de communication Grize (1990) et sur le concept de schématisation développés de la logique naturelle, nous présentons l'analyse d'une revue des médias pour étudier les processus de construction et de co-construction des objets de discours. L'analyse est réalisée en deux étapes: dans le premier, la situation de communication est descrit basée sur les catégories de Charaudeau (2006.2009); dans le second, les processus de construction des objets de discours sont identifiés par l'examen de les mots qui montrent que les représentations pré-construites et culturelles sont mobilisés pour construire le point de vue de l'auteur de l'ouvre - à savoir, la schématisation proposée. Les résultats montrent la productivité que le modèle de la communication de Grize peut donner à l'analyse.

MOTS-CLE: schématisation - objets de discours - analyse de revue des médias.

\section{INTRODUÇÃO}

A resenha é um gênero de discurso sobre o qual muitos estudos têm sido produzidos. Trata-se de um gênero avaliativo e informativo, cuja finalidade é apresentar criticamente uma obra. No entanto, ela não se limita apenas à apresentação dos conteúdos da obra, pressupõe uma "tomada de posição do resenhista sobre o valor e o alcance da obra que está sendo avaliada” (GIERING, 2010, p. 8).

A sua organização discursiva é essencialmente argumentativa, pois um ponto de vista sobre a obra examinada é defendido. Espera-se que o resenhista, além de expor e de

Professora do Curso de Letras da Universidade do Vale do Rio dos Sinos. Mestre em Lingüística aplicada UNISINOS. Doutoranda do Programa de Pós-Graduação em Lingüística Aplicada - UNISINOS. E-mail: skissmann@unisinos.br.

Cadernos do IL. Porto Alegre, n. ${ }^{\circ}$ 42, junho de 2011. p. 171-189.

EISSN:2236-6385

http://www.seer.ufrgs.br/cadernosdoil/ 
descrever, argumente; isto é, apresente um juízo de valor, faça comentários sobre as ideias do autor, julgue as qualidades da obra por meio de provas e de evidências e recomende ou não a sua leitura. Desse modo, a seleção e a organização das informações a serem veiculadas na resenha estão diretamente relacionadas à finalidade discursiva desse gênero de discurso e aos fatores situacionais.

Em função desses aspectos, apresenta-se, neste estudo, a análise da resenha midiática "Navegar é preciso" da obra A origem das espécies de Charles Darwin, produzida pela professora Vera Nisaka Solferini e publicada na revista on-line Com Ciência, em abril de 2009, com base no conceito de esquematização desenvolvido por Grize (1990) a partir da lógica natural. Mesmo que a resenha seja um gênero muito utilizado como objeto de análise, poucos estudiosos têm se dedicado a aplicar o conceito de esquematização para compreender os fenômenos que envolvem a construção e a coconstrução de objetos de discurso, objetivo deste estudo.

O viés teórico escolhido para desenvolver essa análise também se deve ao fato de que vários lingüistas, como Jean Michel Adam (1999), Lorenza Mondada (2002), Daniéle Dubois (2002), Sophie Moirand (2006, 2008) e Denis Apótheloz (1997) tem se apoiado no conceito de esquematização para formular e desenvolver seus modelos teóricos. Entendese, deste modo, que esta análise possa vir a contribuir para os estudos que focalizam o gênero resenha.

A seguir, na seção Pressupostos Teóricos, conceitua-se resenha midiática; descrevese o modelo de comunicação de Grize e seus elementos; explica-se o que é a lógica natural e apresenta-se a noção grizeana de argumentação. Na seção seguinte, fazem-se os encaminhamentos para a análise e apresenta-se a análise; na última seção, as conclusões do estudo são indicadas.

\section{PRESSUPOSTOS TEÓRICOS}

\section{A RESENHA MIDIÁTICA}

A resenha midiática é um gênero discursivo de grande circulação no meio social, é produzida por especialistas em uma área de conhecimento ou por jornalistas para ser veiculada na mídia e é dirigida, normalmente, a um público não especializado, ou seja, a um público mais geral. Uma de suas finalidades é fornecer informações e julgamentos para que o leitor possa se decidir pela leitura ou pela aquisição da obra resenhada. Para comprovar ou não a qualidade da obra, apresentam-se fatos e provas e explicam-se as razões para avaliações positivas ou negativas de forma que a argumentação seja consistente.

Para tratar dos aspectos relevantes da situação de comunicação na qual se inserem as resenhas midiáticas, recorremos à proposta semiolinguística de Patrick Charaudeau.

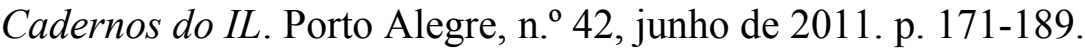


Cadernos do IL e Cadernos do IL e Cadernos do IL e Cadernos do IL e Cadernos do IL o Cadernos do IL

Para o autor, "a construção do sentido, mediante qualquer ato de linguagem, procede de um sujeito que se dirige a outro sujeito, dentro de uma situação de intercâmbio específica, que sobredetermina parcialmente a eleição dos recursos da linguagem que pode usar" (2001, p. 13, grifos do autor).

Desse ato de linguagem, advém a tríplice competência da linguagem: a situacional, a discursiva e a semiolinguística. Para a análise realizada, valemo-nos da competência situacional que focaliza a capacidade de o sujeito que se comunica produzir seu discurso em função: (i) da identidade dos parceiros (Quem se dirige a quem?); (ii) da finalidade da situação de troca (Com que finalidade?); (iii) do propósito (De que se fala?); (iv) das circunstâncias materiais do ato de linguagem. (Em que contexto se inscreve o ato de linguagem? Que canal de comunicação é utilizado?)

\section{O MODELO DE COMUNICAÇÃO DE GRIZE E A LÓGICA NATURAL}

Jean Blaise Grize é um lógico que criou um modelo de comunicação para representar a maneira como ocorre o processo de interação verbal a partir da lógica natural. Para Grize (1996), a lógica natural é uma lógica dos conteúdos, que considera os procedimentos de pensamento que permitem elaborar os conteúdos e relacioná-los entre si, enquanto a lógica formal, baseada em proposições, leva em conta as relações entre os conceitos.

A lógica natural é de natureza descritiva e se baseia no estudo dos textos e dos discursos, porque "o papel da língua não se limita apenas a participar da elaboração de conhecimentos” (ibid., 1996, p. 81), ela instrui os outros, comunica seus pensamentos. Dessa forma, a lógica natural busca descrever as operações de pensamento que servem para construir e para organizar os conteúdos cujos traços estão no discurso.

O conceito-base da lógica natural é o de esquematização, pois pretende dar conta das operações que estão em jogo entre os sujeitos em uma situação de comunicação, operações lógico-discursivas que organizam a esquematização e que são desmembradas em duas famílias: a lógica dos sujeitos e a lógica dos objetos. A análise de um discurso através das operações da lógica natural permite colocar em evidência as configurações da esquematização proposta. Neste estudo, mostra-se como a escolha e o arranjo das palavras estão orientados de forma a permitir que o leitor possa reconstruir a esquematização que lhe é proposta.

Da forma como foi concebida por Grize, a lógica natural pretende tratar de dois aspectos fundamentais: o papel que desempenha o discurso no sentido linguageiro do termo e o papel dos conteúdos. Ela se diferencia de outras disciplinas por ser uma lógica dos sujeitos e uma lógica dos objetos.

A lógica dos sujeitos se serve de uma língua natural, é de natureza essencialmente dialógica, isso implica considerar que, na interação verbal, sempre estão em questão, ao

Cadernos do IL. Porto Alegre, n. ${ }^{\text {o }}$ 42, junho de 2011. p. 171-189.

EISSN:2236-6385 http://www.seer.ufrgs.br/cadernosdoil/ 


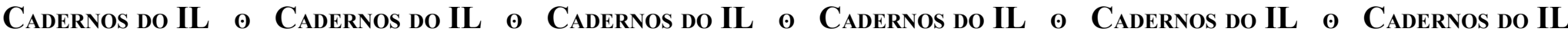

menos, dois sujeitos, em um contexto dado. Para Grize (1990), isso permite e até comanda o emprego de não-ditos e obriga a levar em conta o estatuto dos interlocutores, fato que conduz ao raciocínio pela persuasão bem mais do que pela prova.

A lógica dos objetos refere-se ao fato de que, no decorrer da atividade discursiva, são construídos objetos de pensamento que servirão de referentes comuns aos interlocutores. Ela é uma física do objeto não-qualquer, sempre particular, sempre dotado de um conteúdo específico; opondo-se, dessa maneira, à lógica formal, que é uma física do objeto qualquer.

\begin{abstract}
A lógica natural pode ser definida como o estudo de operações lógico-discursivas que permitem construir e reconstruir uma esquematização. $O$ duplo adjetivo é para sublinhar o fato de que se está em presença de operações de pensamento, mas somente na medida em que esses se expressam através de atividades discursivas. Quanto ao termo operação, ele deve ser tomado em seu sentido matemático. Trata-se sempre de uma aplicação de um conjunto sobre ele mesmo (operação interna) ou em outro conjunto (operação externa). (GRIZE, 1990, p. $65)$
\end{abstract}

Nessa perspectiva, a comunicação é sempre situada. Apoiando-se na natureza dialógica da linguagem enunciada por Bakhtin, o lógico argumenta que "sempre nos expressamos em função de um interlocutor" (ibid., 1990, p. 28). No modelo de Grize (Figura 1), a situação de comunicação representa as circunstâncias materiais nas quais um discurso é produzido e influenciam diretamente a forma e o conteúdo dos enunciados. 
Cadernos do IL e Cadernos do IL e Cadernos do IL e Cadernos do IL e Cadernos do IL o Cadernos do IL

(Fonte: GRIZE, 1990, p. 29)

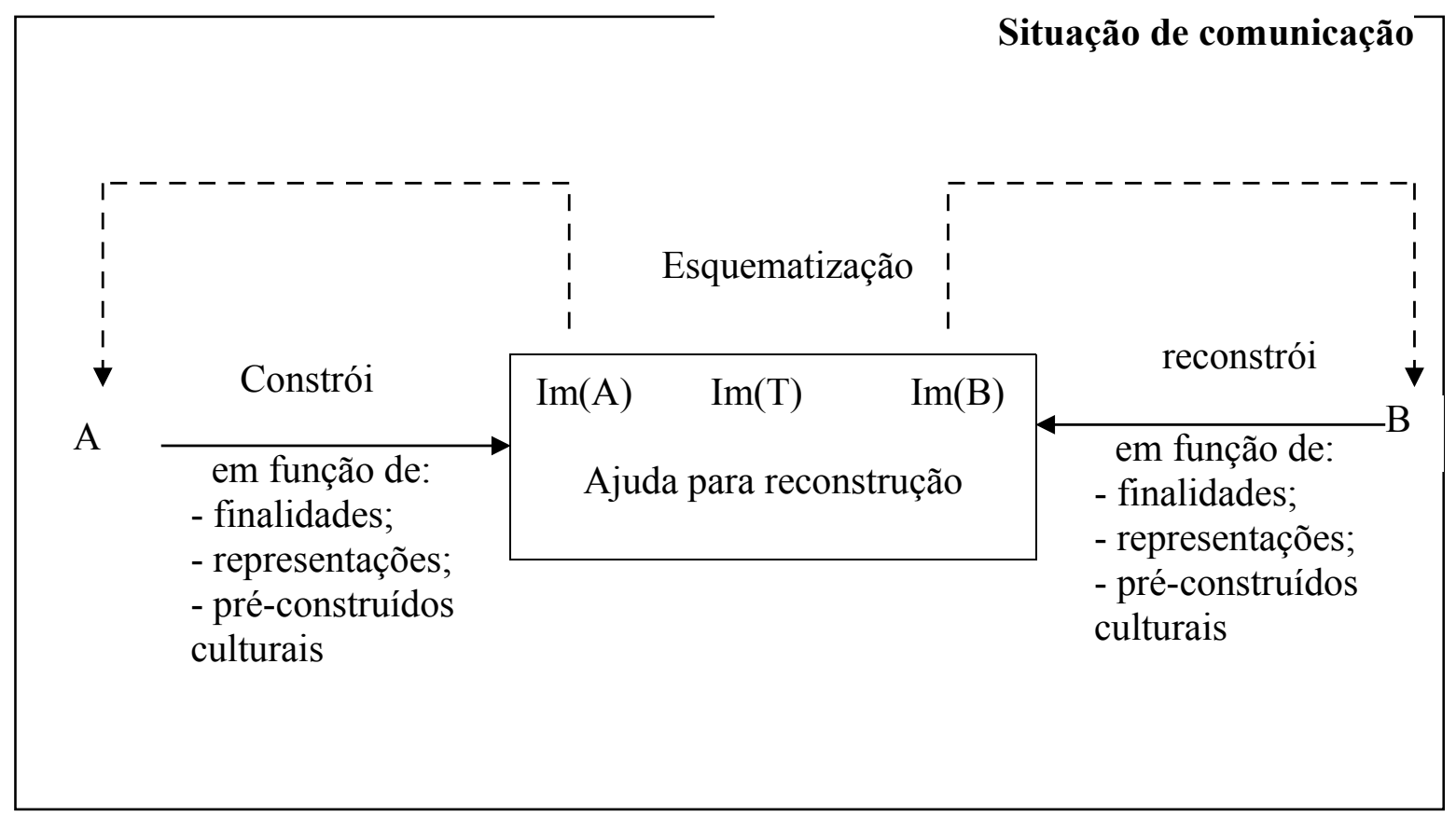

Figura 1 - Esquema de Grize.

Nesse modelo, A e B designam dois lugares que podem ser ocupados, alternadamente, por um indivíduo ou por um grupo, com suas restrições psicológicas e sociais. O lugar de $\mathrm{B}$ também pode ser ocupado por um auditório. $\mathrm{O}$ esquema representa o que acontece quando A tem a palavra; A constrói uma representação discursiva do assunto - uma esquematização - diante de um interlocutor B que reconstrói essa esquematização que lhe é proposta. "Trata-se de sujeitos que desempenham cada um uma atividade: atividade de construção por parte de A e atividade de reconstrução por parte de B" (GRIZE, 1996, p. 68).

O esquema ilustra que, em uma situação de interlocução e diante de um interlocutor $\mathrm{B}$, o locutor A constrói uma representação discursiva do assunto em função da finalidade, dos pré-construídos culturais e das representações que o locutor A possui sobre ele mesmo, sobre o tema e sobre o interlocutor. Por sua vez, o locutor B reconstrói essa esquematização que lhe é proposta em função da esquematização, da finalidade, das representações e dos pré-construídos culturais. Entretanto, deve-se considerar que a reconstrução que B faz da esquematização proposta por A pode não ter a mesma forma, porque os interlocutores são seres distintos, reais e únicos e a comunicação não é um processo simétrico, há uma série de fatores que tomam parte desse processo e que o determinam. A assimetria entre A e B se deve ao fato de que a finalidade de A é diferente

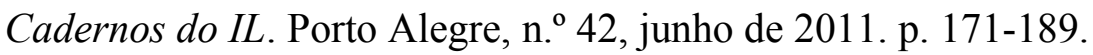


Cadernos do IL e Cadernos do IL e Cadernos do IL e Cadernos do IL e Cadernos do IL o Cadernos do IL

da finalidade de B, visto que A é aquele que toma a iniciativa do ato de comunicação e B está restrito ao que A lhe propôs.

\section{OS PRÉ-CONSTRUÍDOS CULTURAIS, AS FINALIDADES, AS REPRESENTAÇÕES E A ESQUEMATIZAÇÃO}

Os pré-construídos culturais relevam o fato de que, ao usarmos a língua, estamos manipulando signos que já remetem a um sentido, e esse sentido, na visão de Grize, é préconstruído e é de natureza cultural, ou melhor, as palavras de uma língua natural possuem um núcleo suficientemente comum que permite a comunicação. Ao usar a língua, mobilizase um conjunto de conhecimentos, que se convertem em todo tipo de experiências de natureza essencialmente cultural e social.

"Os pré-construídos culturais fornecem um quadro obrigatório dentro do qual o discurso deve se inserir e, pelo duplo mecanismo de assimilação e de acomodação, o orador organiza os conteúdos de acordo com uma intenção de dizer" (ibid., 1996, p. 66). Trata-se do sentido das palavras; das ligações e dos lugares comuns que são indispensáveis para sustentar os raciocínios, mesmo os mais elementares, que permitem a compreensão.

As finalidades representam o fato de que sempre temos uma razão, escutamos ou lemos algo por algum motivo, mesmo quando "jogamos conversa fora" só para passar o tempo. Passar o tempo é uma finalidade, o motivo que nos levou a conversar. A finalidade de uma resenha midiática é apresentar o ponto de vista do resenhista sobre a obra em análise, recomendando ou não a sua leitura. As finalidades de $\mathrm{A}$ e de $\mathrm{B}$ produzem efeitos sobre a construção e a reconstrução de uma esquematização, pois é sabido que falamos ou escrevemos de maneira diferente se queremos elogiar, repreender, entre outros.

As representações indicam que, ao interagir, é necessário conhecer o assunto sobre o qual se fala e ter, pelo menos, algum tipo de ideia ou representação daquele ao qual nos dirigimos. Considerando os fatores intervenientes no processo de comunicação, é necessário que o locutor tenha ou faça para si uma representação do tema, do ouvinte e dele mesmo, porque não falamos da mesma forma se estamos, por exemplo, constrangidos ou seguros de nós mesmos - ou seja, assume-se uma posição, um estatuto diante do interlocutor. No caso da resenha midiática, o produtor do texto tem representações sobre quem é o seu leitor, sobre o tema da obra e sobre o próprio papel que ele, resenhista, desempenha ao escrever uma resenha. Os interlocutores A e B possuem representações e o discurso propõe imagens; no entanto, essas imagens são parciais, nunca se representa uma pessoa, mas alguns de seus aspectos: conhecimentos, propósitos, valores.

$\mathrm{O}$ fato de termos três termos envolvidos no processo de comunicação (A, B e T) implica relações distintas entre eles, das quais o locutor também deve ter uma representação. Dessa forma, temos o seguinte conjunto de representações: (i) a relação $(\mathrm{A}, \mathrm{B})$ reflete as relações de força que se estabelecem em um determinado contexto; (ii) a

Cadernos do IL. Porto Alegre, n. ${ }^{\text { 4 }}$ 2, junho de 2011. p. 171-189.

EISSN:2236-6385

http://www.seer.ufrgs.br/cadernosdoil/ 
Cadernos do IL e Cadernos do IL e Cadernos do IL e Cadernos do IL e Cadernos do IL o Cadernos do IL

relação $(\mathrm{B}, \mathrm{T})$ reflete a atitude de $\mathrm{B}$ em relação ao tema em questão; (iii) a relação $(\mathrm{A}, \mathrm{T})$ também tem um papel importante, pode expressar dúvida, certeza, crença, as quais não são equivalentes (exemplo: não se fala com convicção quando não acreditamos naquilo que estamos dizendo).

Nesse modelo, está previsto que B reconstrói a esquematização proposta por A; portanto, B também deve fazer para si representações de A, de B, de $\mathrm{T}$ e da relação AB; temos, então, o seguinte conjunto de representações: (i) a representação que B faz do tema para si mesmo é essencial (ela pode bloquear ideias falsas); (ii) a representação que B faz de $\mathrm{A}$ é base para o argumento de autoridade. Como A não tem acesso às representações de $\mathrm{B}$, o locutor A considera as representações que ele faz para si das representações de B; nas palavras de Grize, isso implica um "grau de complexidade complementar" (1990, p. 34). Nessa perspectiva, A pode assumir diferentes imagens: locutor como fonte de seus ditos; como simples testemunha; como neutro ou engajado. É possível, para A, manipular a sua imagem e a de seus destinatários (GRIZE, 1996).

As finalidades, os pré-construídos culturais e as representações, neste esquema, servem de base para a construção da esquematização, que é uma atividade criadora de sentido, é feita diante do interlocutor e é a ele destinada. Deve ser entendida como um processo e como um resultado. Como processo implica uma organização do material verbal que remete a pré-construídos culturais para ordenar o sentido - é uma semiose; como resultado, remete à apresentação de um microuniverso ao interlocutor. No processo de feedback, em que o locutor B reconstrói a esquematização que lhe é proposta, A pode, a cada instante, reformular o que diz, em função da reconstrução de B, ou seja, o que A acabou de dizer determinará parcialmente o que segue, o que caracteriza uma atividade de coconstrução do objeto de discurso.

Nessa perspectiva, o sentido é organizado em função da finalidade, isto é, o locutor seleciona, dentro do "núcleo" comum das palavras, os traços que definirão o efeito de sentido desejado. Esse núcleo comum das palavras corresponde aos pré-construídos culturais. A esquematização é, também, um resultado, propõe a criação de um microuniverso em função das representações dos indivíduos situados nos lugares A e B; "esquematizar um aspecto da realidade, fictícia ou não, é um ato de semiótica, é dar a ver" (id., 1990, p. 37).

Toda esquematização tem efeitos de sentido sobre o interlocutor, que deduz ideias, sentimentos, consentimentos, reprovações, entre outros. O locutor propõe signos na intenção de fazer sentido, mas é o interlocutor quem lhes dá sentido, num processo dinâmico de construção e de coconstrução. Esquematizar é construir uma representação discursiva, por definição parcial, seletiva e estratégica, de uma realidade. Se a esquematização dá a ver, é aquele quem olha que lhe dá um sentido, pois "todo aquele que fala ou escreve expõe necessariamente seu olhar" (ibid., 1990, p. 36). O locutor não tem qualquer garantia de que o interlocutor vá reconstruir a esquematização exatamente como ela foi proposta.

Cadernos do IL. Porto Alegre, n. ${ }^{\text { 4 }}$ 2, junho de 2011. p. 171-189. 
O discurso, nesta visão, é criação de sentidos e é construído por objetos de pensamento a partir da significação dos termos dos quais ele se serve, além de ser sempre situado. Esses objetos de pensamento são formados por signos e por referentes aos quais remetem, constituindo os referenciais do discurso, que devem ser comuns ou partilhados pelos interlocutores.

A construção dos objetos é uma coconstrução que resulta de uma ultrapassagem dos pontos de vista ou, pelo menos, de sua conjugação. A atividade discursiva é fundamentalmente dialógica de forma que a imagem que o discurso dá de seus objetos é sempre mais ou menos aquela da estereoscopia, isto é, não é uma simples transferência de informações. Toda ação supõe uma finalidade que explora parte da indeterminação dos signos da língua. Os objetos de uma argumentação são sempre objetos ad hoc, ou seja, preparados para satisfazer certos propósitos e mobilizam, na atividade de coconstrução, dois procedimentos: a filtragem e a saliência. "Filtrar é reter alguns aspectos de representações e ocultar outros. Salientar é servir-se de formas da língua para fixar a atenção em algo" (Grize, 1996, p. 68). Em outras palavras, "construir uma esquematização é, de um lado, selecionar certos elementos; de outra parte, fixar a atenção nos meios linguísticos" (GRIZE, 1996, p. 68).

\section{ARGUMENTAR NA PERSPECTIVA DA LÓGICA NATURAL}

Argumentar é fornecer argumentos, razões para sustentar uma tese e envolve operações como: explicar, justificar, reforçar, sustentar, entre outras. No escopo da lógica natural, a argumentação é vista como uma tentativa que visa a intervir sobre a opinião, sobre a atitude, sobre o comportamento de alguém. Trata-se de um agir sobre o interlocutor com o propósito de partilhar um ponto de vista em que se modificam diversas representações, evidenciando-se alguns aspectos das coisas e ocultando-se outros, mediante uma esquematização apropriada.

Toda argumentação visa a intervir sobre aquele ao qual é dirigida, que é um parceiro ativo. Por isso, determina a mobilização de competências: (i) competência lingüística (capacidade de falar a língua, usar o léxico, a sintaxe e os conhecimentos pragmáticos); (iii) competência cultural (conhecimentos enciclopédicos); (iii) competência retórica (capacidade de utilizar metáforas); (iv) competência lógica (capacidade de fazer inferências). Ela também deve permitir que o interlocutor possa receber, aceitar e aderir ao que lhe é proposto.

Receber consiste em reconstruir a esquematização, ou seja, conhecer a língua e atribuir sentido ao que foi dito. Para tanto, faz-se necessário o emprego das competências linguística, cultural, retórica e enciclopédica. Aceitar a esquematização proposta consiste em não apresentar objeções, construir a esquematização e compreender com assentimento; sem possibilitar contradiscurso, é da ordem do convencimento - estou convencido de que o

Cadernos do IL. Porto Alegre, n. ${ }^{\circ}$ 42, junho de 2011. p. 171-189. 
que dizes está correto. Quando A propõe a esquematização, é preciso que ele se esforce para impedir que B formule um contradiscurso, ou seja, evitar que B possa dizer "Isso que me é proposto não se sustenta" ou "Eu não creio nisso" (GRIZE, 1990, p. 42).

Em sentido amplo, uma argumentação visa à eficácia e não ao conhecimento da verdade; aquilo que é verdadeiro para um pode não ser necessariamente para outro, pois o universo de crenças nem sempre é similar, ou seja, os universos de crenças dos interlocutores não são sempre coincidentes e não estão sobrepostos, há mundos possíveis diferentes.

A aceitação de um fato como verdadeiro depende diretamente da situação de comunicação, ou seja, toda asserção leva em conta um contexto preestabelecido. Na perspectiva da argumentação, um fato é o que o orador dá como tal, sem se arriscar a uma explicação ou a uma justificação - o fato deve se impor. O locutor deve mostrá-lo ao interlocutor, pois ele se inscreve em um sistema de valores; além disso, o orador instaura uma autoridade que lhe é exterior - na resenha objeto de exame, a resenhista é uma especialista na área, o que lhe confere competência e credibilidade para realizar a análise crítica da obra.

Aceitar a esquematização não é ainda aderir. A adesão demanda mais que a não objeção; reclama uma participação inteira do interlocutor. Ele não somente reconstrói a esquematização, mas a recria. Aderir é tomar como sua a esquematização, é ser persuadido. É levar em consideração o desejo, o afeto, a emoção. Para tanto, o locutor utiliza os valores do destinatário e se serve da retórica.

Aderir a uma esquematização não é só evitar um contradiscurso. Trata-se de fazer com que o interlocutor, além de reconstruir a esquematização, faça inferências sobre os ditos e os não-ditos, recriando toda a esquematização. Esse processo de reconstrução da esquematização é sempre situado e é comandado pelos mecanismos de elucidação que constituem "um conjunto de procedimentos discursivos que devem conduzir o ouvinteleitor a inferir um julgamento de valor" (GRIZE, 1990, p. 48) e pertence a ordem da Retórica ${ }^{1}$. Segundo Moirand (2008, p. 34), "a elucidação é dada através da escolha de palavras e das construções das atividades de nomeação, de caracterização e de avaliação feitas pelo enunciador e, dessa forma, participa da esquematização construída no fio do discurso".

Dentre os mecanismos de elucidação que resultam de mecanismos linguageiros múltiplos elencados por Grize, interessa-nos, neste estudo, os procedimentos lexicais, as especificações e as contaminações. Os procedimentos lexicais dizem respeito ao fato de que as palavras assumem valores em função do domínio da troca e das circunstâncias pragmáticas, ou seja, é relevante as inferências que o campo permite fazer.

\footnotetext{
${ }^{1}$ Grize, no capítulo 7, assinala que Aristóteles foi quem desenvolveu o objetivo do gênero deliberativo - o
} útil e o prejudicial; do gênero judiciário - o justo e o injusto; e do gênero epidíctico - o belo e o feio. 
Quando se vai falar de um objeto para lhe atribuir qualquer propriedade ou para colocá-lo em relação com qualquer outro, deve-se escolher, dentro da língua, nomes de objetos, de propriedades ou de verbos. Pode-se discutir a questão de saber se existem termos neutros ou se todos são, de alguma forma, esclarecidos positiva ou negativamente. (GRIZE, 1996, p. 49)

As especificações colocam em relevo um aspecto do objeto por diversos procedimentos gramaticais, como a aposição, o emprego da oração relativa, ou seja, tudo aquilo que caracteriza o objeto. Há três tipos de contaminações: (i) por comparação; (ii) por metáfora; (iii) por metonímia (sinédoque), as quais destacam um aspecto do objeto.

Ao estudar o papel da memória e sua inscrição na materialidade discursiva, ao tentar responder à questão: que memórias intervêm no fio do texto, na construção e na compreensão dos textos, a linguista Sophie Moirand (2008) articula as noções de interdiscurso $^{2}$ e de dialogismo ${ }^{3}$ às noções de esquematização, de elucidação e de objetos de discurso de Grize.

A alusão permite a evocação de dizeres, de fatos e de eventos e, portanto, de domínios de memória e de saberes, os seus traços funcionam como índices de contextualização. No fio do discurso, elas podem elucidar o ponto de vista do produtor do texto sobre os fatos que ele evoca por meio de palavras e dizeres que ele toma emprestado; essa memória de palavras e de dizeres contribui para a elucidação que o enunciador dá aos objetos de discurso que são construídos na organização do material verbal (MOIRAND, 2008).

No tratamento da progressão da esquematização, intervêm, de distintas formas, diferentes memórias, as quais podem ser recuperadas pela alusão. As formas de alusão não são de natureza estritamente discursiva e não se podem excluir as bases cognitivas da memória na construção midiática das relações entre discurso e história. As alusões podem constituir traços (i) de representações que o enunciador se faz de universos de crenças, de conhecimentos ou de experiências dos destinatários e (ii) do tratamento cognitivo prévio à produção do discurso efetuado pelo enunciador com suas lembranças e seus esquecimentos. Ao mesmo tempo, elas constituem, para os destinatários, signos de evocação de representações fundadas em seu espaço mental e em índices de contextualização necessários à compreensão de fatos, de eventos e de formas de designá-los, de relatá-los e de avaliá-los (MOIRAND, 2008).

\section{ENCAMINHAMENTOS PARA ANÁLISE}

\footnotetext{
${ }^{2}$ Ver PÊCHEUX, M. Análise automática do Discurso. In: GADET, F; HAK, T. (Orgs.). Por uma análise automática do discurso: uma introdução à obra de Michel Pêcheux. Campinas: Editora da UNICAMP, 1993.

${ }^{3}$ Ver BAKHTIN, M. Estética da criação verbal. São Paulo: Martins Fontes, 1992.
}

Cadernos do IL. Porto Alegre, n. ${ }^{\text { 4 }}$ 2, junho de 2011. p. 171-189. 
Considerando os pressupostos apresentados, a análise realizada divide-se em dois momentos. No primeiro, utilizam-se as categorias indicadas por Charaudeau (2006) para caracterizar o quadro situacional que determinou a produção da resenha midiática "Navegar é preciso". No segundo, descrevem-se os processos utilizados para a construção do objeto de discurso - neste caso, a avaliação que a resenhista apresenta da obra em exame - e que evidenciam a esquematização proposta.

\section{PRIMEIRO MOMENTO: A SITUAÇÃO DE COMUNICAÇÃO}

A resenha "Navegar é preciso"4 foi veiculada na revista eletrônica de jornalismo científico Com Ciência ${ }^{5}$, publicação da Sociedade Brasileira para o Progresso da Ciência (SPBC) em parceria com o Laboratório de Estudos Avançados em Jornalismo da Unicamp (Labjor). A revista trata de assuntos relacionados a todas as áreas das ciências e, a cada mês, aborda um tema específico, com reportagens e artigos relacionados ao assunto; também possui uma seção de notícias que é atualizada semanalmente. Segundo os editores, "o público alvo da revista Com Ciência é constituído por estudantes dos ensinos médio e universitário, por pesquisadores, docentes e pessoas interessadas em ciência de um modo geral". A revista insere-se em um contexto midiático, é uma publicação dirigida a um público geral; mas também é direcionada, como os próprios editores apontam, a especialistas, a professores e a estudantes.

O tema principal da edição em análise (abril de 2009) é o evolucionismo. O assunto foi tratado por diversos especialistas e com enfoques distintos. Há reportagens e artigos assinados por pesquisadores sobre "os caminhos atuais do evolucionismo", sobre a "biologia evolutiva" e uma entrevista com o físico e teólogo Eduardo Rodrigues Cruz. Para completar a edição, veicula-se a resenha da obra $A$ origem das espécies, publicada por Charles Darwin em 1859, feita pela professora Vera Nisaka Solferini.

A resenha "Navegar é preciso", que apresenta criticamente a obra de Charles Darwin, está de acordo com a orientação temática da edição, já que o livro é a obra que descreve a teoria da evolução. A resenhista é pesquisadora do Departamento de Genética e Evolução do Instituto de Biologia da Universidade Estadual de Campinas (Unicamp). Trata-se de uma profissional com amplo domínio do assunto, tanto por sua formação acadêmica - possui mestrado, doutorado e pós-doutorado em Ciências Biológicas (Genética e Evolução) -, quanto por sua atuação profissional: ela é professora de pós-graduação na área de Genética Evolutiva e pesquisadora do CNPQ.

\footnotetext{
4 Disponível em http://www.comciencia.br/comciencia/handler.php?section=8\&edicao=45\&id=41\&tipo= resenha.

${ }^{5}$ Todas as edições da revista podem ser acessadas no site: www.comciencia.br.
}

Cadernos do IL. Porto Alegre, n. ${ }^{\text { 4 }}$ 42, junho de 2011. p. 171-189. 
A composição da resenha e a seleção das informações apresentadas são orientadas pelos conhecimentos que a resenhista possui sobre a organização desse gênero e pelo fim comunicacional característico da resenha midiática: apresentar a obra criticamente ao leitor.

A seguir, reproduzimos a resenha.

\section{(01) NAVEGAR É PRECISO ${ }^{6}$}

Vera N. Solferini ${ }^{7}$

(02) Em uma longa viagem, Darwin compreendeu o princípio básico de evolução dos seres vivos e deixou, para as gerações futuras, uma obra que vai além da origem da vida.

(03) A origem das espécies, de Charles Darwin é, talvez, a obra que mais influenciou a produção intelectual a partir de sua publicação em 1859. (04) E não se trata de exagero fazer tal afirmação, uma vez que não somente a biologia, mas outras ciências foram profundamente influenciadas pelos estudos do naturalista inglês.

(05) Para tentar avaliar a dimensão da obra, podemos divagar sobre o que teria acontecido se ela nunca tivesse sido escrita. (06) A biologia, sem dúvida, seria diferente. (07) Também a política e a psicologia, pois $O$ capital não teria sido escrito, uma vez que Karl Marx e Friedrich Engels foram influenciados pela leitura de $A$ origem das espécies, assim como foi Sigmund Freud, que iniciou suas pesquisas inspirado na obra de Darwin. (08) Todas as formas de manifestação científica, cultural ou artística ocidentais de alguma maneira foram influenciadas por este livro. (09) Começa a ficar difícil, se não impossível, o exercício de imaginar a nossa cultura sem $A$ origem das espécies.

(10) Claro que sempre há o argumento válido de que a ciência inevitavelmente levaria à teoria evolutiva - tanto que Alfred Russel Wallace também chegou, simultaneamente, às mesmas conclusões que Darwin. (11) Mesmo assim, é difícil conceber que o trabalho de Wallace pudesse ter o mesmo impacto.

(12) Isso porque o que fez deste um livro tão especial é, em primeiro lugar, o seu autor. (13) Darwin era um estudioso detalhista, meticuloso, obsessivo, determinado, consciente das consequências de sua teoria e por elas atormentado. (14) A viagem do navio Beagle durou quase 5 anos (1831-1836). (15) Durante esse período, Darwin passou por diversos continentes e, só depois de duas longas décadas de trabalho e árduas reflexões, publicou o que seria "uma versão reduzida" de sua obra. (16) Nela, cada tópico foi apresentado com inúmeros exemplos, evidências, resultados de experimentos e trocas de ideias com outros cientistas. (17) Cada conceito foi incansavelmente desenvolvido de modo

6 Texto publicado na revista Com Ciência, São Paulo, n. 107, abr. 2009. Disponível em $<$ http://www.comciencia.br/comciencia/handler.php?section=8\&edicao=45\&id=41\&tipo=resenha.>. Acesso em: 03 set. 2009.

${ }^{7}$ Vera Nisaka Solferini é professora do Departamento de Genética e Evolução do Instituto de Biologia da Universidade Estadual de Campinas (Unicamp).

Cadernos do IL. Porto Alegre, n. ${ }^{\circ}$ 42, junho de 2011. p. 171-189.

EISSN:2236-6385 http://www.seer.ufrgs.br/cadernosdoil/ 
a não haver possibilidade de interpretações dúbias. (18) Embora, na sua época, a ideia de um mundo biológico dinâmico, com espécies mudando ao longo do tempo geológico, não fosse bem uma novidade, A origem das espécies trouxe, como todos sabem, a proposta de um mecanismo para explicar tais mudanças: a seleção natural. (19) Essa foi a novidade: por ação da seleção natural as espécies se modificam ao longo do tempo e podem formar novas espécies.

(20) Darwin começa o livro discorrendo sobre a variação nas espécies domesticadas e sobre hereditariedade, cujas leis lhe eram desconhecidas. (21) Ao estender o conceito para os organismos selvagens, ele discute o significado da variação geográfica, as dificuldades com os conceitos de espécie, de subespécie e de variedade (para ele pouco importa o nome que se dê a um "conjunto de formas duvidosas"). (22) O capítulo III desenvolve a ideia de "luta pela sobrevivência", mas, além da competição inter e intra-específicas, também aborda as relações complexas entre animais e plantas. (23) Não dá para apresentar todos os conceitos que surgem ao longo do livro, mas vale ressaltar que inúmeros aspectos da biologia dos organismos foram considerados como, por exemplo, anatomia comparada, comportamento, embriologia, registro geológico e distribuição geográfica (que hoje tem o nome de biogeografia). (24) Darwin também enfatiza o surgimento, ao acaso, da variação e o papel da reprodução sexuada, mantendo a coesão das espécies, e do isolamento geográfico, promovendo a formação de novas espécies. (25) Em resumo: Charles Darwin abordou inúmeros conceitos importantes da biologia, embora tenha ficado famoso por suas teses mais polêmicas, sobretudo por apontar nosso parentesco com os demais primatas.

(26) Hoje em dia, é difícil encontrar quem não conheça tais ideias. (27) A teoria da evolução, a seleção natural, a sobrevivência do mais forte, dentre outras, são expressões frequentes nos mais diversos ambientes. (28) Foram inclusive distorcidas e utilizadas como explicações pseudo-científicas para justificar atos de discriminação racial e injustiça social, sob o nome de "darwinismo social". (29) Mesmo hoje, seu nome é invocado por alguns fundamentalistas para fomentar a polêmica discussão "você acredita em Deus ou em Darwin?", numa tentativa de desacreditar e enfraquecer a teoria evolutiva, fortalecendo o criacionismo.

(30) Polêmicas à parte, na biologia, nada faz sentido senão à luz da evolução. (31) É a teoria evolutiva que unifica o conhecimento biológico ao considerar os organismos atuais como resultado de um longo processo de evolução orgânica a partir de um único ancestral comum.

(32) Considerando tudo isso, a importância de $A$ origem das espécies e o fato de ser uma obra muito citada, é surpreendente perceber que se trata de um livro que quase ninguém leu. Entenda-se que o fato de somente "alguns terem lido" é, no mínimo, decepcionante - pelo menos entre biólogos e estudantes de biologia. (33) Mas, talvez, isso não seja completamente por acaso.

(34) O livro de Darwin não é exatamente o tipo de texto que prende o leitor jovem. Não é um livro de ação, ou suspense; não tem efeitos especiais e a maioria das edições não

Cadernos do IL. Porto Alegre, n. ${ }^{\text { 4 }}$ 2, junho de 2011. p. 171-189. 
Cadernos do IL e Cadernos do IL e Cadernos do IL e Cadernos do IL e Cadernos do IL o Cadernos do IL

vêm ilustradas. (35) Em resumo: a primeira vista pode parecer muito chato. (36) Sem paciência para ler, mas consciente de que o deveria ter feito, a pessoa se apropria de alguns chavões e sequer tem coragem de iniciar a empreitada.

(37) Foi tentando estimular a leitura da $A$ origem entre alunos de graduação que percebi que basta um pouco de orientação e de motivação para as páginas começarem a virar. (38) Apreciar este livro envolve conhecer seu momento histórico e entender a organização de seus capítulos; aos poucos vamos descobrindo que a "chatice" é, na verdade, característica de um autor metódico, incansável na explicação de suas ideias e que esmiúça os assuntos detalhadamente. (39) Cada capítulo começa com um sumário, e a maioria se encerra com um resumo, o que facilita bastante a compreensão quando o texto se torna muito extenso. Muitas vezes é o resumo que motiva a retomada do texto.

(40) Ler $A$ origem das espécies é uma constante surpresa. (41) É descobrir que há muito mais neste livro do que a famosa seleção natural. (42) É descobrir, por exemplo, que a propalada controvérsia "darwinismo-lamarckismo" não faz sentido da maneira como é apresentada, pois ainda que Darwin não concordasse com algumas propostas de Lamarck (como o surgimento constante das formas mais simples por geração espontânea), ele aceita "uso e não-uso" atuando nas mudanças morfológicas.

(43) Outro ponto importante que fica claro para quem leu a $A$ origem é que nem todas as características de um organismo estão sujeitas à ação da seleção natural. (44) Isso pode soar muito estranho para quem procura uma explicação adaptativa em tudo, mas pode ser muito interessante para quem consegue ver Darwin ressaltar a utilidade das características sem importância fisiológica para a classificação dos organismos (hoje, as hipóteses filogenéticas são construídas a partir de caracteres neutros, por exemplo).

(45) A leitura da obra $\boldsymbol{A}$ origem das espécies hoje não deixa de ser um exercício de humildade. (46) De perceber que a maioria das questões evolutivas, sobre as quais trabalhamos atualmente, de algum modo, foram notadas por Darwin. (47) Trabalhar a leitura da $\boldsymbol{A}$ origem com os alunos tem me trazido muita satisfação. (48) Uma vez quebrada a resistência inicial, muitas descobertas vão sendo feitas. (49) É uma leitura indispensável para o biólogo, mesmo quando ele se concentra apenas na evolução orgânica. (50) Para as demais almas, é uma obra que vale a pena...

\section{SEGUNDO MOMENTO: ANÁLISE DOS PROCESSOS EMPREGADOS NA CONSTRUÇÃO DO OBJETO}

O título da resenha "Navegar é preciso" faz alusão ao poema do poeta português Fernando Pessoa e ao fato de que Darwin navegou a bordo do navio Beagle ${ }^{8}$ durante quase cinco anos para observar a natureza e o comportamento das espécies, o que resultou na

${ }^{8}$ Nome do navio usado por Darwin em sua expedição.

Cadernos do IL. Porto Alegre, n. ${ }^{\circ}$ 42, junho de 2011. p. 171-189.

EISSN:2236-6385 http://www.seer.ufrgs.br/cadernosdoil/ 
teoria da evolução. Após o título, no subtítulo, há uma indicação sobre a viagem realizada por Darwin, o que permite que o leitor faça a construção de sentido, ou seja, há uma complementação do que foi apresentado.

Considerando-se o leitor da revista, essa alusão poderá ser reconstruída ou não, uma vez que se baseia em conhecimentos supostamente partilhados pelo leitor, ou seja, não se pode garantir que o leitor, ao reconstruir a esquematização proposta, perceba a alusão.

A finalidade da resenha é avaliar criticamente a obra $A$ origem das espécies de Charles Darwin e sustentar uma posição. No texto, a resenhista recomenda a leitura e realiza vários procedimentos a fim de indicar o livro aos leitores. Percebe-se que a autora, ao escrever para um leitor projetado, ora se dirige a aqueles que não leram a obra e que deveriam ler, ora àqueles que deveriam recomendar a obra aos seus alunos e que não o fazem.

Nos enunciados 3 e 4, a resenhista apresenta a obra e a situa como referência para a área de estudos, isso se dá por meio das expressões "obra que mais influenciou a produção intelectual" e "não se trata de exagero". Ela organiza as informações de forma que o leitor, ao recriar a esquematização proposta, perceba a importância da obra resenhada.

$\mathrm{Na}$ sequência, no enunciado 5, a resenhista apresenta uma série de acontecimentos que só se tornaram reais em função da publicação do livro. Ao mesmo tempo em que convida o leitor a "divagar" com ela (uso do verbo flexionado na primeira pessoa do plural - "podemos divagar") sobre o que poderia ter ocorrido, caso Darwin não tivesse escrito o livro, através do emprego da forma condicional "se", na oração "se ela nunca tivesse sido escrita".

Nos segmentos 6, 7 e 8, cita personagens da história que são mundialmente reconhecidos (Karl Marx, Friedrich Engels, Sigmund Freud) e suas obras, além de mencionar a biologia, a política e a psicologia - campos de estudos relevantes no âmbito das ciências. Ao fazer essa menção, a resenhista ancora-se: (i) em uma representação positiva que os leitores têm desses autores; (ii) em um pré-construído cultural sobre a importância das obras desses autores para a humanidade; (iii) em uma representação do alcance da obra de Darwin ao influenciar obras de campos tão distintos. Todas essas ações são organizadas para sustentar o seu argumento: "todas as formas de manifestação científica e cultural ou artística ocidentais de alguma maneira foram influenciadas por este livro", o que conduz a conclusão de que "Começa a ficar difícil, se não impossível, o exercício de imaginar a nossa cultura sem A origem das espécies".

Nos enunciados 10, 11 e 12, dirige-se a um público mais especializado, menciona um pesquisador (Alfred Russel Wallace) que não é tão conhecido do público geral, ou seja, ela se antecipa ao leitor especializado (professor, pesquisador) dizendo conhecer que há correntes que acreditam que tal pesquisador também poderia ter desenvolvido a teoria da evolução das espécies, isso se evidencia pelo uso das expressões "claro que", "inevitavelmente". No entanto, ela não crê ser possível comparar Darwin e Wallace e utiliza a construção concessiva "mesmo assim" para assinalar a sua discordância com essa

Cadernos do IL. Porto Alegre, n. ${ }^{\text { 4 }}$ 2, junho de 2011. p. 171-189. 
posição e a explicita afirmando: "isso porque o que faz deste um livro tão especial é, em primeiro lugar, o seu autor".

Na sequência, nos enunciados 13, 14, e 15, a autora passa a descrever o autor da obra examinada - ação exigida pelo gênero discursivo resenha - e a viagem realizada que o levou a elaboração do livro $A$ origem das espécies. Ela utiliza a sequência "estudioso detalhista, meticuloso, obsessivo, determinado, consciente das conseqüências de sua teoria e por elas atormentado" para caracterizar o autor; ela constrói uma representação discursiva singular e elogiosa do cientista, considerando os atributos que são exigidos de um pesquisador.

No trecho seguinte, nas sentenças 16, 17 e 18, temos uma breve apresentação da obra - também uma ação exigida pelas características do gênero - seguida de comentários e de avaliações sobre o seu conteúdo, que podem ser evidenciadas pelas expressões: "inúmeros exemplos" e "incansavelmente". No enunciado 18, a autora utiliza a expressão "como todos sabem" para indicar a grande contribuição da obra e conseguir a adesão do leitor à tese que ela defende: vale a pena ler a obra.

A resenhista, nos enunciados compreendidos entre as linhas 20 e 24, passa a fazer uma descrição detalhada da obra, resume brevemente o conteúdo dos seus capítulos e tece comentários sobre sua qualidade. Nesse segmento, flexiona os verbos no presente para ilustrar o que Darwin fez em cada parte de sua obra; no entanto, no enunciado 25, para finalizar a descrição, flexiona o verbo no passado e faz um fechamento do que é a obra, ao mesmo tempo em que destaca o seu argumento: "Charles Darwin abordou inúmeros conceitos importantes da biologia, embora tenha ficado famoso por suas teses mais polêmicas, sobretudo por apontar nosso parentesco com os demais primatas". Nesse enunciado, a expressão "teses mais polêmicas" indica uma representação de que o leitor conheça as controvérsias que envolvem a obra de Darwin e como elas têm sido tratadas hoje em dia. Esse fato é reforçado no enunciado 26, quando a autora enuncia: "Hoje em dia, é difícil encontrar quem não conheça tais ideias".

Entretanto, considerando o leitor que não saiba sobre o que a autora trata quando menciona "teses mais polêmicas" - provavelmente o estudante -, a resenhista passa a relacionar quais são esses conceitos mais controversos (enunciados 27, 28 e 29). A menção a esses fatos, por outro lado, também desempenha o papel de mostrar para o leitor que a ela não desconhece esses aspectos; no entanto, eles não são suficientes para desqualificar o mérito da obra.

No enunciado 30 "Polêmicas à parte, na biologia, nada faz sentido senão à luz da evolução", a autora marca, de forma categórica, o fato de que a teoria da evolução é fundamental para a biologia e a sua posição a esse respeito. No enunciado seguinte (31), "É a teoria evolutiva que unifica o conhecimento biológico ao considerar os organismos atuais como resultado de um longo processo de evolução orgânica a partir de um único ancestral comum", a autora justifica a sua posição por meio de explicação.

Cadernos do IL. Porto Alegre, n. ${ }^{\text { 4 }}$ 2, junho de 2011. p. 171-189. 
Até esta parte da resenha, a autora se dedicou a apresentar as razões para sustentar o seu ponto de vista, para o qual ela espera a adesão do leitor. A seleção e a organização das informações foram conduzidas de forma que o leitor possa reconstruir a esquematização proposta e partilhar do mesmo ponto de vista da resenhista. A obra é recomendada de forma explícita e vários elogios são tecidos sobre o seu conteúdo e a sua relevância não só para o desenvolvimento da Biologia como também o desenvolvimento de outras ciências é destacado.

Na sequência, a autora passa a questionar o motivo pelo qual ela não é lida e utiliza esse "espanto" como um argumento para ratificar a sua tese. Essa ideia está veiculada no enunciado 32:

Considerando tudo isso, a importância de $A$ origem das espécies e o fato de ser uma obra muito citada, é surpreendente perceber que se trata de um livro que quase ninguém leu. Entenda-se que o fato de somente "alguns terem lido" é, no mínimo, decepcionante - pelo menos- entre biólogos e estudantes de biologia.

Ao mencionar que a obra é pouco lida, apesar de ser excelente, revela ter ciência dessa situação e se propõe a discorrer sobre as causas que envolvem essa questão, fato comprovado por meio do uso da conjunção opositiva "mas" e do advérbio de dúvida "talvez" no enunciado 33: "Mas, talvez, isso não seja completamente por acaso". Nos enunciados 34, 35 e 36, essas causas são apresentadas através da enumeração das características da obra que não são atrativas para o leitor jovem: "Não é um livro de ação, ou suspense; não tem efeitos especiais e a maioria das edições não vêm ilustradas" - ao fazer tais considerações, dirige-se aos jovens (estudantes) e revela a imagem que tem desses leitores.

Nas sentenças seguintes, indica como a leitura da obra poderia ser estimulada, percebe-se que ela se dirige a dois leitores: o estudante e o professor.

Foi tentando estimular a leitura da $A$ origem entre alunos de graduação que percebi que basta um pouco de orientação e de motivação para as páginas começarem a virar. Apreciar este livro envolve conhecer seu momento histórico e entender a organização de seus capítulos; aos poucos vamos descobrindo que a "chatice" é, na verdade, característica de um autor metódico, incansável na explicação de suas ideias e que esmiúça os assuntos detalhadamente. Cada capítulo começa com um sumário, e a maioria se encerra com um resumo, o que facilita bastante a compreensão quando o texto se torna muito extenso. Muitas vezes é o resumo que motiva a retomada do texto.

$\mathrm{Na}$ sentença 40, por meio de um conjunto de predicações, afirma que ler a obra é "uma constante surpresa" e, nos próximos segmentos, apresenta uma lista de descobertas que a leitura pode proporcionar, além de apresentar conceitos e análises que pressupõem a representação de um leitor especializado - mais uma vez a resenhista parece dirigir-se ao professor com o firme propósito de convencê-lo a ler a obra com os seus alunos.

Cadernos do IL. Porto Alegre, n. ${ }^{\circ}$ 42, junho de 2011. p. 171-189. 
Para finalizar, a resenhista busca a adesão do leitor também pela emoção, ao dizer que a leitura da obra $A$ origem das espécies de Charles Darwin é um "exercício de humildade". Ela também se implica pessoalmente na argumentação, tornando-a sua: "Trabalhar a leitura da $A$ origem tem me trazido muita satisfação". Então, a autora não restringe a recomendação da leitura da obra somente ao público especializado e aos estudiosos do campo da biologia, ela conclui argumentando que "para as demais almas, é uma obra que vale a pena...".

\section{CONSIDERAÇÕES FINAIS}

Neste estudo, tínhamos por objetivo aplicar o conceito de esquematização na análise de uma resenha midiática cujo propósito é apresentar criticamente uma obra. A análise realizada revela que o modelo de comunicação desenvolvido por Grize e o conceito de esquematização fornecem subsídios produtivos que nos permitem explicar os diferentes processos que são mobilizados na construção de objetos de discurso.

Além disso, a análise realizada sob a perspectiva da lógica natural permite mostrar que um conjunto de pré-construídos culturais e de representações é acionado pelo produtor do texto com o propósito de permitir que o interlocutor - o leitor da resenha - possa reconstruir a esquematização de forma que ela seja a mais próxima possível daquela que lhe foi proposta.

Em seu modelo de comunicação, Grize atribui um papel fundamental ao interlocutor; nessa proposta, é ele o responsável pela construção de sentidos. Nessa abordagem, o discurso propõe imagens, ou seja, o locutor propõe a esquematização - no caso da resenha examinada, a representação discursiva do ponto de vista da resenhista de que vale a pena ler o livro $A$ origem das espécies de Charles Darwin -; no entanto, é responsabilidade do interlocutor atribuir um sentido a essa representação. O interlocutor precisa inferir e criar sentido, a partir de representações e de imagens que o locutor lhe apresenta.

A análise revela que a seleção e a organização das informações foram feitas de forma que o interlocutor pudesse receber, aceitar e aderir a argumentação que lhe é proposta - considerando-se que a resenhista ora se dirige ao leitor especialista (professor e pesquisador), ora se dirige ao leitor não especialista (estudante). Valendo-se dos recursos linguístico-discursivos oferecidos pela língua, a resenhista mobilizou pré-construídos e representações culturais para construir a esquematização e, ao mesmo tempo, evitar o contradiscurso a fim de: (i) provar para o leitor por que motivos a obra $A$ origem das espécies de Charles Darwin deve ser lida; e (ii) persuadir o leitor a ler a obra e concordar com a tese que ela sustenta ao longo de toda a resenha - fato que corrobora a tese de Grize

Cadernos do IL. Porto Alegre, n. ${ }^{\circ}$ 42, junho de 2011. p. 171-189.

EISSN:2236-6385 http://www.seer.ufrgs.br/cadernosdoil// 


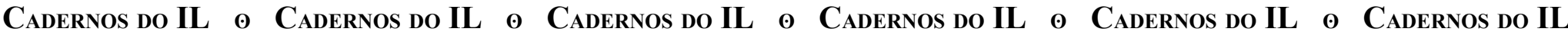

de que a argumentação está sempre presente na situação de comunicação e de que o interlocutor pode ser concebido como alguém sobre o qual se age para partilhar uma visão.

Para finalizar, destaca-se que não se pode conceber uma situação de comunicação sem considerar a dupla atividade dos parceiros e sem se interrogar sobre as operações postas em jogo em uma esquematização. Esse modelo, portanto, leva em conta o funcionamento e o emprego das formas verbais em relação à situação de comunicação e à finalidade discursiva e permite formular as hipóteses sobre os raciocínios que conduzem essa escolha e os seus efeitos na construção do discurso.

\section{REFERÊNCIAS}

ADAM, J.-M. Entre énoncé et énonciation: la schématisation. In: Linguistique Textuelle : des genres de discours aux textes. Paris: Nathan, 1999, p. 101-118. CHARAUDEAU, P. O discurso das mídias. São Paulo: Contexto, 2006. . Linguagem e discurso: modos de organização. São Paulo: Contexto, 2009. De la competência social de comunicación a las competencias discursivas. Revista Lationoamericana de Estúdios del Discurso, Caracas, v.1, n. 1, p. 7-22, ago. 2001. GIERING, M. E. A resenha acadêmica. In: ALVES, I. M. da R.; GIERING, M. E. MELLO, V. H. D. (Orgs.) Leitura e produção de resenha acadêmica. São Leopoldo, RS: Editora UNISINOS, 2010. GRIZE, J.-B. Logique et langage. Paris: Ophrys, 1990. 1996. . Logique natureelle et communications. Paris: Presses Universitaires de France,

MOIRAND, S. Discours, mémoires et contextes: à propos du fonctionnment de l'allusion dans la presse. Estudos da Língua(gem), v. 6, n. 1, jun. 2008, p. 7-46.

MONDADA, L. ; DUBOIS, D. Constructions des objets de discours et catégorisation: une approche des processus de référenciation. Revista de Letras, v. 1/2, n. 24, jan/dez. 2002.

SOLFERINI, Vera N. Navegar é preciso. Revista Com Ciência. São Paulo, n. 107, abr. 2009. Disponível em : <http://www.comciencia.br/comciencia/handler.php? section $=8 \&$ edicao $=45 \& \mathrm{id}=41 \&$ tipo $=$ resenha $>$. Acesso em: 03 set. 2009.

Cadernos do IL. Porto Alegre, n. ${ }^{\circ}$ 42, junho de 2011. p. 171-189. 